Published in final edited form as:

Pediatr Res. 2020 November ; 88(5): 733-738. doi:10.1038/s41390-020-1052-х.

\title{
Serial Assessment of Fat and Fat-free Mass Accretion in Very Preterm Infants: A Randomized Trial
}

\author{
Ariel A. Salas ${ }^{1}$, Maggie L. Jerome ${ }^{2}$, Paula Chandler-Laney ${ }^{2}$, Namasivayam Ambalavanan ${ }^{1}$, \\ Waldemar A. Carlo ${ }^{1}$ \\ ${ }^{1}$ Department of Pediatrics, University of Alabama at Birmingham, Birmingham, AL 35249, \\ ${ }^{2}$ Department of Nutrition Sciences, University of Alabama at Birmingham, Birmingham, AL 35249.
}

\begin{abstract}
Background: Clinicians could modify dietary interventions during early infancy by monitoring fat and fat-free mass accretion in very preterm infants.

Methods: Preterm infants were randomly assigned to either having reports on infant body composition available to the clinicians caring for them (intervention group) or not having reports available (control group). All infants underwent serial assessments of body composition by airdisplacement plethysmography before 32 weeks of postmenstrual age (PMA) and at 36 weeks PMA. The primary outcome was percent body fat $(\% \mathrm{BF})$ at 3 months of corrected age $(\mathrm{CA})$.

Results: Fifty infants were randomized (median gestational age: 30 weeks; mean \pm SD birth weight: $1387 \pm 283 \mathrm{~g}$ ). The mean $\% \mathrm{BF}$ increased from $7 \pm 4$ before 32 weeks PMA to $20 \pm 5$ at 3 months $\mathrm{CA}$. The differences in mean $\% \mathrm{BF}$ between the intervention group and the control group were not statistically significant at 36 weeks PMA (14.5 vs. 13.6) or 3 months CA (20.8 vs. 19.4). Feeding practices and anthropometric measurements during hospitalization did not differ between groups.
\end{abstract}

Conclusions: Serial assessments of body composition in both intervention and control groups showed consistent increments in \%BF. However, providing this information to clinicians did not influence nutritional practices or growth.

Users may view, print, copy, and download text and data-mine the content in such documents, for the purposes of academic research, subject always to the full Conditions of use:http://www.nature.com/authors/editorial_policies/license.html\#terms

Corresponding author: Ariel A. Salas, Division of Neonatology, University of Alabama at Birmingham, 1700 6th Ave South, Women \& Infants Center Suite 9380, Birmingham AL 35233, phone: 205-934-4680, fax: 205-934-3100, asalas@ peds.uab.edu. Authors' contributions: AAS: conceptualized and designed the study, carried out the analysis, and drafted the initial manuscript; MJ: designed the data collection instruments, monitored patient enrollment and compliance, collected and analyzed nutritional data, and completed follow-up visits; PCL, NA, and WAC: helped design the study and critically reviewed the manuscript; and all authors: read and approved the final manuscript.

Disclosure statement: AAS received honoraria from the Lockwood Group LLC for participation in advisory board meetings. AAS and PCL filed a patent application for an instrumented feeding bottle. WAC is on the board of directors of MEDNAX Services, Inc.

Category of study: Clinical.

Clinical Trial Registration: ClinicalTrials.gov: NCT03575897

Impact: Serial assessments of body composition in preterm infants at 32 and 36 weeks postmenstrual age show consistent increments in \% body fat up to 3 months of corrected age. However, providing this information to the clinician did not influence nutritional practices or growth. 


\section{INTRODUCTION}

Clinicians in the neonatal unit have the ability to effectively control all external sources of nutrition in the immediate neonatal period. However, having this type of control has not led to significant reductions in postnatal growth failure at 36 weeks of postmenstrual age (PMA). Postnatal growth failure (weight $<10^{\text {th }}$ percentile) occurs in up to $60 \%$ (1-3) of the nearly 80,000 infants born preterm at 32 weeks of gestation or less every year in the United States (4).

To prevent postnatal growth failure, clinicians often prescribe high-calorie diets to promote weight gain between 15 and $20 \mathrm{~g} / \mathrm{kg} / \mathrm{d}$ in preterm infants (5). This nutritional practice is common across neonatal units, but the practice of assessing the effects of weight gain on body composition using air-displacement plethysmography (ADP) is not. A comprehensive evaluation of postnatal growth with infant body composition could help guide dietary interventions for infants at high risk of excessive weight gain and rapid body fat accretion that may ultimately increase the risk of obesity and long-term related morbidities (6-9). Currently, assessment of body composition is neither part of the usual care of preterm infants in neonatal units nor part of screening programs to monitor body composition of infants with a history of prematurity in follow-up clinics.

We hypothesized that, by monitoring fat and fat-free mass accretion before and after hospital discharge in very preterm infants ( 28 to 32 weeks of gestation), clinicians could modify dietary interventions in early infancy, promote fat-free mass (FFM) accretion, and prevent excessive fat mass (FM) accretion $(10,11)$. The specific aims of this pilot trial were to evaluate the feasibility of serial assessments of body composition in the routine care of preterm infants and to determine if providing information on body composition to clinicians could guide dietary interventions and improve growth outcomes of preterm infants.

\section{SUBJECTS AND METHODS}

\section{Trial design}

This study was a parallel-group randomized controlled trial in which preterm infants were randomly assigned to either intervention or control group with a 1:1 allocation ratio. The study protocol was approved by the University of Alabama at Birmingham (UAB) Institutional Review Board (IRB).

\section{Participants}

Very preterm infants with gestational ages between 28 and 32 weeks of gestation admitted to the neonatal unit at the UAB hospital located in Birmingham, Alabama were included. Infants with gastrointestinal malformations, central nervous system malformations, or terminal illness needing to limit or withhold support were excluded.

\section{Randomization, allocation concealment, and masking}

Prior to randomization, written parental consent was obtained within the first week after birth. A computer-generated, random-block sequence was used to randomize study participants. Numbered, opaque, sealed envelopes were opened in sequential order to 
allocate the study intervention. Twin infants were randomized individually. The study intervention was not masked.

\section{Interventions}

All infants underwent serial assessments of body composition during their stay in the neonatal unit. The first assessment was performed between birth and 32 weeks of postmenstrual age (PMA), and the subsequent assessment was performed at 36 weeks PMA or hospital discharge, whichever occurred first. Infants randomly assigned to the intervention group had the information about infant body composition available for the clinicians caring for them (including reference data). Infants randomly assigned to the control group had this information about infant body composition collected, but it was not available for the clinicians caring for them.

\section{Primary and secondary outcomes}

The primary outcome was percent body fat (\%BF) estimated by ADP at 3 months of corrected age (CA). Other pre-specified secondary outcomes were FM, FFM, and \%BF at 36 weeks PMA or hospital discharge (whichever occurred first), postnatal growth failure (below $10^{\text {th }}$ percentile) at 36 weeks PMA or discharge, weight gain $(\mathrm{g} / \mathrm{kg} / \mathrm{d})$ from birth to 36 weeks PMA estimated by using the exponential method (12), and anthropometric measurements at 36 weeks PMA (weight, head circumference, and length).

\section{Study procedures}

For infants in the intervention group, written reports were prepared 1 to 4 days after the assessment date and presented to front-line clinicians (i.e., residents or nurse practitioners) caring for the infant. Clinicians were instructed to discuss the body composition report during multidisciplinary rounds in subsequent days. Weight, length, $\% \mathrm{BF}$, and percentile values were included in the report. Information on FFM was not included.

Only infants who did not require intravenous fluids or respiratory support had ADP assessments of body composition. Serial assessments of infant body composition were performed with the PeaPod ${ }^{\circledR}$ (Life Measurement Instruments, Concord, CA) (13). For inpatient assessments, nursery staff and parents, if present, transported the infant from the neonatal unit to the exam room within the same building where the PeaPod® is located. For outpatient assessments at 3 months of age, a follow-up visit was scheduled prior to discharge from the hospital.

\section{Control or monitoring of co-interventions}

Clinical care and decisions about nutritional practices were conducted at the discretion of the attending neonatologist. During the trial, enteral nutrition was initiated at $20-30 \mathrm{ml} / \mathrm{kg} / \mathrm{d}$ for 1 to 3 days and then advanced by $20-30 \mathrm{ml} / \mathrm{kg} / \mathrm{d}$ until full enteral nutrition was established (>150 ml/kg/d). Bovine-based fortifiers were added to human milk when enteral nutrition reached 100 to $120 \mathrm{ml} / \mathrm{kg} / \mathrm{d}$. If the supply of human milk was insufficient to advance enteral nutrition, $24 \mathrm{kcal} / \mathrm{oz}$ preterm formula was prescribed. Donor milk was not offered. Enteral nutrition was discussed daily during family-centered rounds and weekly during multidisciplinary rounds that included a registered dietitian. 


\section{Sample size}

A sample size of 46 patients was considered necessary to detect a 3-point difference in \%BF between groups with SD of 3.6, 0.05 level of significance, and $80 \%$ power. In anticipation of a loss to follow-up rate close to $10 \%, 2$ patients were added to each group and the sample size was increased to 50 .

\section{Statistical methods}

This trial recorded core data on nutrition, as recommended by consensus groups $(12,14)$. For analysis of the primary outcome, an unadjusted t-test comparison of the mean ${ }^{\%} \mathrm{BF}$ between control and intervention groups was performed. A similar approach was used for secondary outcomes. Descriptive data was expressed as the mean (SD) or number (percentage) of observations. A pre-specified MANOVA analysis was performed to determine within subject and between subjects variability in the repeated measures model. The primary statistical analyses were performed using JMP software, version 14.1 (SAS Institute Inc., Cary, NC).

\section{RESULTS}

Fifty very preterm infants were randomized (Figure 1). The mean \pm SD birth weight was $1387 \pm 283 \mathrm{~g}$, and the median gestational age was 30 weeks (IQR: $30-32$ weeks). A set of triplets born at 28 weeks of gestation who needed non-invasive respiratory support during the first weeks after birth were not assessed by 32 weeks PMA. The number of infants without a body composition assessment at 36 weeks PMA did not differ between groups. Nine infants were not assessed at 36 weeks PMA or discharge due to an unexpected, 6-week long, maintenance problem with the PeaPod ${ }^{\circ}$. Sociodemographic characteristics did not differ between groups (Table 1). Approximately one-third of the infants included (16 of 50) were the product of multiple gestations ( 3 sets of twins, 2 sets of triplets, and 1 set of quadruples). Most infants received mother's milk as primary source of nutrition during the first weeks after birth and achieved enteral feeding volumes $>120 \mathrm{ml} / \mathrm{kg} / \mathrm{day}$ by postnatal day 8 .

Between birth and 32 weeks PMA, 45 of 50 infants had a body composition assessment. Three of these infants had a weight of less than $1000 \mathrm{~g}$ at the time of assessment. The median postnatal age at the first assessment was $12 \mathrm{~d}$ (IQR: $10-14 \mathrm{~d}$ ), around 32 weeks PMA. At 36 weeks PMA or hospital discharge (whichever occurred first), 35 of 50 infants had a body composition assessment. The median postnatal age at the second assessment was 35 d (IQR: $28-40$ d), around 36 weeks PMA. At 3 months CA, 25 of 50 infants had a body composition assessment. The mean \%BF between birth and 32 weeks PMA was $6.7 \pm 3.6$, the mean $\% \mathrm{BF}$ at 36 weeks PMA was $14.2 \pm 3.7$, and the mean $\% \mathrm{BF}$ at 3 months $\mathrm{CA}$ was $19.9 \pm 4.8$. Mean differences in $\% \mathrm{BF}$ between the intervention group and the control group were not statistically significant at 36 weeks PMA $(+0.9$ favoring the intervention group; 95\% CI: $-1.7-3.5 ; \mathrm{p}=0.49)$ or 3 months CA (+1.5 favoring the intervention group; $95 \% \mathrm{CI}$ : $-2.6-5.5 ; \mathrm{p}=0.46$ ) (Figure 2). In a MANOVA analysis, neither variability between subjects $(\mathrm{p}=0.26)$ nor variability within subjects $(\mathrm{p}=0.89)$ explained the effects observed across the repeated measurements of $\% \mathrm{BF}$. The correlation between $\% \mathrm{BF}$ at 36 weeks PMA and \%BF 
at 3 months CA was low ( $\mathrm{r}=0.32$ ). Significant differences in FFM accretion between groups were not found. BF, FM, and FFM $z$ scores at 3 months CA or 52 weeks PMA were closer to sex-specific reference values available for preterm infants of the same postnatal age (i.e. 3 months CA) (15) and they did not differ significantly between groups (Figure 3).

Around the time of the first body composition assessment, the median caloric intake was $113 \mathrm{cal} / \mathrm{kg} / \mathrm{d}$ (IQR: $105-125 \mathrm{cal} / \mathrm{kg} / \mathrm{d}$ ) and the median protein intake was $1.7 \mathrm{~g} / \mathrm{kg} / \mathrm{d}$ (IQR: $1.5-4 \mathrm{~g} / \mathrm{kg} / \mathrm{d}$ ). These median values did not differ significantly between groups. By the time of the second body composition assessment, the median protein intake increased by 1 $\mathrm{g} / \mathrm{kg} / \mathrm{d}$ (IQR: $0-2.7 \mathrm{~g} / \mathrm{kg} / \mathrm{d}$ ) and the median caloric intake increased by $6 \mathrm{cal} / \mathrm{kg} / \mathrm{d}$ (IQR: 0 $22 \mathrm{cal} / \mathrm{kg} / \mathrm{d}$ ) in both groups. There were no significant differences in these increments between groups.

After comparing baseline characteristics between infants with missing data and infants with complete data for the outcome of $\% \mathrm{BF}$ at 3 months $\mathrm{CA}$, we determined that black infants were less likely to return for follow-up ( $35 \%$ vs. $63 \%$; $\mathrm{p}=0.05)$ and that only 7 of 16 infants who were the product of multiple gestations returned for follow-up assessments at 3 months CA.

Feeding practices and growth outcomes during hospitalization did not differ between groups (Table 2). The median postnatal age at discharge was $48 \mathrm{~d}$ (IQR: $36-59 \mathrm{~d}$ ), around 37 weeks PMA. No harms or unintended effects of the study intervention were found. Of 23 infants that required respiratory support during the first weeks after birth, 11 were supported with non-invasive ventilation, 9 were supported with mechanical ventilation, and 3 were supported with supplemental oxygen only. None of the infants received postnatal steroid treatment. Similarly, no episodes of culture-proven sepsis were documented. One case of stage 1 necrotizing enterocolitis and one case of grade 1 intraventricular hemorrhage were reported. No other serious events occurred before discharge.

\section{DISCUSSION}

This randomized pilot trial that compared the current standard of care with the practice of monitoring changes in infant body composition from birth to hospital discharge in very preterm infants ( 28 to 32 weeks of gestation) failed to identify the impact of serial assessments of body composition during the hospital stay on infant weight gain, nutritional practices, growth outcomes, and infant body composition at 3 months CA.

The negative results of this pilot trial need a careful interpretation. By not including the body composition reports in the electronic medical records (EMRs), we limited the clinicians' ability to access and review the results during rounds. Also, we did not standardize the reporting on changes in body composition during rounds. Moreover, we did not include specific dietary recommendations in the reports, and the dietitian assigned to the unit was unaware of the allocated intervention and, therefore, unable to provide dietary recommendations according to changes in body composition during multidisciplinary rounds. The 3 to 4-week interval between assessments could also explain the negative results reported in this trial. A trial with body composition assessments at more frequent intervals 
and standardized reporting of both FM and FFM gains in the EMR system could be more supportive of our conclusions.

Our hypothesis was based on an improved understanding of the interaction between dietary interventions, infant weight gain, and body fat accretion. Preventing postnatal growth failure with diets that promote excessive weight gain in developing infants (5) might increase susceptibility to early metabolic reprogramming of adverse health outcomes (16-18) including hypertension, insulin resistance (19), and disproportionate increase of body fat $(17,20)$. Cohort studies that followed preterm infants from birth to adulthood reported higher blood pressure values, higher rates of insulin resistance, and higher body fat in adults born preterm compared to term controls $(9,21)$. Increased body fat in preterm infants has also been documented at term CA and during early infancy (22), a critical period for infant development. The definition of excessive weight gain depends on the target growth. If the nutritional goal is to prevent postnatal growth failure and achieve growth patterns similar to the ones observed in fetuses of the same gestational age, a weight gain of 15 to $20 \mathrm{~g} / \mathrm{kg} / \mathrm{d}$ can be considered adequate and a weight gain $>20 \mathrm{~g} / \mathrm{kg} / \mathrm{d}$ can be considered excessive (23). Conversely, if the nutritional goal is to achieve growth patterns similar to the ones observed in healthy preterm infants, a weight gain $>15 \mathrm{~g} / \mathrm{kg} / \mathrm{d}$ may be unnecessary and, therefore, considered excessive (24). One half of the preterm infants included in our trial had postnatal growth failure at 36 weeks PMA and most experienced weight gain below recommended targets (i.e., $15 \mathrm{~g} / \mathrm{kg} / \mathrm{d}$ ). Under these circumstances, detecting disproportionate increase of body fat among preterm infants is more challenging. Many would argue that insufficient weight gain could potentially affect neurodevelopment of preterm infants. However, several randomized trials of dietary interventions that prevented growth failure through adequate weight gain failed to identify benefits on neurodevelopment $(17,25-27)$. These findings demand caution with the assumption that promoting brain development through weight gain outweighs the risk of potential long-term metabolic dysfunction. Although we could not determine whether weight gain of 15 to $20 \mathrm{~g} / \mathrm{kg} / \mathrm{d}$ increases body fat accretion in preterm infants, we provide preliminary information on body composition outcomes in early infancy, a high-priority field of nutrition research. Because the collective nutritional goal for preterm infants in many neonatal units is to promote adequate weight gain between 15 to $20 \mathrm{~g} / \mathrm{kg} / \mathrm{d}$ that some may consider excessive, a future trial comparing specific targets of weight gain could help elucidate the effects of excessive weight gain on body composition of preterm infants.

We chose very preterm infants as the ideal study population for this trial because their risk for adverse health outcomes is moderate $(6,9)$, their need for supplemental oxygen after birth is usually resolved by postnatal day 7, and their diets between birth and hospital discharge are strictly controlled for more than 30 days. This trial confirmed most of these assumptions. The majority of infants stayed in the hospital for more than 30 days and $90 \%$ of them had their first assessment of body composition by postnatal day 10 .

We selected infant body composition at 3 months of age as the primary outcome of the trial because at this age non-invasive methods to assess body fat are available, follow-up rates are usually high, physical activity and other risk factors for overweight and obesity are generally inconsequential, and measurements of body fat accretion are strongly correlated with 
measurements at 2 years of age. Recent studies suggest that changes in body composition after hospital discharge could be an important tool to analyze long-term health risks of excessive weight gain during early development (28). We confirmed that \% BF assessed within the first month after birth in preterm infants is significantly higher than \%BF assessed within the first few days after birth in term infants (15). We also confirmed that by 52 weeks PMA, the differences in body composition between term and preterm infants are minimal $(29,30)$. However, the implications of these early and transient differences in body fat accretion remain unknown.

Serial assessment of infant body composition using ADP in a randomized clinical trial is one of the strengths of this trial. Currently, ADP is the less invasive method to assess infant body composition $(13,31)$. With ADP, reference values of adiposity expressed as $\% \mathrm{BF}$ at different gestational ages have been determined $(22,32)$. They range from $6 \%$ at 30 weeks of gestation to $9.5 \%$ at 37 weeks of gestation $(15,32)$. Others have used low-accuracy methods to assess infant body composition (22) and have suggested that weight data can predict FFM and FM (33). However, several studies that measured body composition with ADP have concluded that anthropometric data cannot predict neonatal adiposity $(34,35)$.

Another strength of this trial is that we calculated the sample size needed using our institutional data of $\% \mathrm{BF}$ among preterm infants. Because the average difference in $\% \mathrm{BF}$ between term and preterm infants is usually $3 \%(22)$, we estimated that a $3 \%$ absolute difference between groups would be clinically meaningful. Although we selected $\% \mathrm{BF}$ as the primary outcome of this trial, we recognize that other outcomes of body composition in early infancy (i.e., FFM accretion) may also be critical and superior to traditional growth outcomes associated with long-term health. FFM accretion as a result of weight gain has been linked with improved neurodevelopment (36). Body mass index (BMI) is widely accepted to define obesity in many populations. However, in early infancy, BMI has poor predictive accuracy for childhood obesity and a weak correlation with body fat. Because high BMI correlates with high FFM and BMI explain only up to $43 \%$ of the variation in FM among term infants $(35,37)$, reducing BMI to prevent obesity in early infancy is not currently recommended (38). Body fat accretion as a result of excessive weight gain might have a stronger correlation with overweight and other adverse health outcomes at school age (39).

The main limitations of the study were the single-center study design, the higher than expected loss to follow-up, the small sample size, and the lack of information on other anthropometric measurements such as skin folds and thigh/arm circumferences. Our nutritional practices may differ from nutritional practices in other units. Others have reported that preterm infants can have mean $\% \mathrm{BF}$ values as high as $17 \%$ at 36 weeks PMA. The large amount of breast milk feeding observed during the trial could explain the lower mean \%BF values reported. We showed that access to body composition data did not influence decisions on dietary interventions in our unit. However, others may implement more dietary interventions based on changes in body composition. Likewise, our respiratory practices that allowed ADP assessments soon after birth in very preterm infants likely differ from those observed in other units. Only a few studies have validated ADP assessments before 32 weeks PMA. Our follow-up rates at 3 months CA among very preterm infants were lower than our 
follow-up rates at 24 months among extremely preterm infants (approximately $80 \%$ at our institution). Our small sample size affected the precision of our estimates and reduced the external validity of our results, but our maximized efforts to improve the accuracy of our results increased their internal validity.

While incorporating longitudinal assessment of infant body composition into current practices of neonatal care is innovative, more research is still needed to determine if monitoring changes in body composition could reduce the risk of overweight and obesity in very preterm infants. Future studies promoting weight gain with hospital-based nutritional interventions should report data on infant body composition. Reports of qualitative and quantitative outcomes of growth will determine if close monitoring of body composition during infancy can guide clinical decision-making and define patient-specific nutritional support that balances neurodevelopmental benefit and metabolic risk.

In summary, our results indicate that assessing body composition at intervals defined by ongoing clinical research (i.e., birth to 32 weeks and 36 weeks or discharge) neither reduces variability in nutritional practices nor minimizes the risk of excessive body fat accretion in preterm infants. These results suggest that assessments of body composition at more frequent intervals may be needed to make meaningful changes to dietary interventions and thus affect body composition in infancy.

\section{Statement of financial support:}

This trial was supported by a research award from the National Institute on Minority Health and Health Disparities (NIMHD) through the UAB Health Disparities \& Obesity Research Center (2U54MD000502).

\section{REFERENCES}

1. Clark RH, Thomas P, Peabody J. 2003 Extrauterine growth restriction remains a serious problem in prematurely born neonates. Pediatrics 111:986-990. [PubMed: 12728076]

2. Ehrenkranz RA, et al. 2006 Growth in the neonatal intensive care unit influences neurodevelopmental and growth outcomes of extremely low birth weight infants. Pediatrics 117:1253-1261. [PubMed: 16585322]

3. Navarrete CT, et al. 2016 Growth Outcomes of Preterm Infants Exposed to Different Oxygen Saturation Target Ranges from Birth. J Pediatr 176:62-68 e64. [PubMed: 27344218]

4. Hamilton BE, Martin JA, Osterman MJ. 2016 Births: Preliminary Data for 2015 Natl Vital Stat Rep 65:1-15.

5. Embleton NE, Pang N, Cooke RJ. 2001 Postnatal malnutrition and growth retardation: an inevitable consequence of current recommendations in preterm infants? Pediatrics 107:270-273. [PubMed: 11158457]

6. Parkinson JR, Hyde MJ, Gale C, Santhakumaran S, Modi N. 2013 Preterm birth and the metabolic syndrome in adult life: a systematic review and meta-analysis. Pediatrics 131:e1240-1263. [PubMed: 23509172]

7. Euser AM, et al. 2005 Associations between prenatal and infancy weight gain and BMI, fat mass, and fat distribution in young adulthood: a prospective cohort study in males and females born very preterm. Am J Clin Nutr 81:480-487. [PubMed: 15699238]

8. Kerkhof GF, Willemsen RH, Leunissen RW, Breukhoven PE, Hokken-Koelega AC. 2012 Health profile of young adults born preterm: negative effects of rapid weight gain in early life. J Clin Endocrinol Metab 97:4498-4506. [PubMed: 22993033]

9. Morrison KM, et al. 2016 Cardiometabolic Health in Adults Born Premature With Extremely Low Birth Weight. Pediatrics 138. 
10. Isong IA, et al. 2018 Racial and Ethnic Disparities in Early Childhood Obesity. Pediatrics 141.

11. Karaolis-Danckert N, et al. 2006 Rapid growth among term children whose birth weight was appropriate for gestational age has a longer lasting effect on body fat percentage than on body mass index. Am J Clin Nutr 84:1449-1455. [PubMed: 17158429]

12. Cormack BE, Embleton ND, van Goudoever JB, Hay WW Jr., Bloomfield FH. 2016 Comparing apples with apples: it is time for standardized reporting of neonatal nutrition and growth studies. Pediatr Res 79:810-820. [PubMed: 26866908]

13. Demerath EW, Fields DA. 2014 Body composition assessment in the infant. Am J Hum Biol 26:291-304. [PubMed: 24424686]

14. Koletzko B, et al. 2015 Core data necessary for reporting clinical trials on nutrition in infancy. Ann Nutr Metab 66:31-35.

15. Norris T, et al. New charts for the assessment of body composition, according to air-displacement plethysmography, at birth and across the first 6 mo of life. Am J Clin Nutr 109:1353-1360.

16. Tarry-Adkins JL, Ozanne SE. 2011 Mechanisms of early life programming: current knowledge and future directions. Am J Clin Nutr 94:1765S-1771S. [PubMed: 21543536]

17. Ong KK, et al. 2015 Postnatal growth in preterm infants and later health outcomes: a systematic review. Acta Paediatr 104:974-986. [PubMed: 26179961]

18. Wiedmeier JE, Joss-Moore LA, Lane RH, Neu J. 2011 Early postnatal nutrition and programming of the preterm neonate. Nutr Rev 69:76-82. [PubMed: 21294741]

19. Bayman E, Drake AJ, Piyasena C. 2014 Prematurity and programming of cardiovascular disease risk: a future challenge for public health? Arch Dis Child Fetal Neonatal Ed 99:F510-514. [PubMed: 25135955]

20. Kashyap S, et al. 2001 Effects of quality of energy intake on growth and metabolic response of enterally fed low-birth-weight infants. Pediatr Res 50:390-397. [PubMed: 11518827]

21. Raju TNK, et al. 2017 Adults born preterm: a review of general health and system-specific outcomes. Acta Paediatr 106:1409-1437. [PubMed: 28419544]

22. Johnson MJ, Wootton SA, Leaf AA, Jackson AA. 2012 Preterm birth and body composition at term equivalent age: a systematic review and meta-analysis. Pediatrics 130:e640-649. [PubMed: 22891222]

23. Fenton TR, et al. 2018 An Attempt to Standardize the Calculation of Growth Velocity of Preterm Infants-Evaluation of Practical Bedside Methods. J Pediatr 196:77-83. [PubMed: 29246464]

24. Villar J, et al. 2019 Growth of preterm infants at the time of global obesity. Arch Dis Child 104:725-727. [PubMed: 30032114]

25. Biasini A, et al. 2012 Growth and neurological outcome in ELBW preterms fed with human milk and extra-protein supplementation as routine practice: do we need further evidence? J Matern Fetal Neonatal Med 25 Suppl 4:72-74.

26. Lucas A, Morley R, Cole TJ. 1998 Randomised trial of early diet in preterm babies and later intelligence quotient. BMJ 317:1481-1487. [PubMed: 9831573]

27. Lucas A, Morley R, Cole TJ, Gore SM. 1994 A randomised multicentre study of human milk versus formula and later development in preterm infants. Arch Dis Child Fetal Neonatal Ed 70:F141-146. [PubMed: 8154907]

28. Scheurer JM, et al. 2017 Body Composition Trajectories From Infancy to Preschool in Children Born Premature Versus Full-term. J Pediatr Gastroenterol Nutr 64:e147-e153. [PubMed: 28045768]

29. Ramel SE, et al. 2011 Body composition changes in preterm infants following hospital discharge: comparison with term infants. J Pediatr Gastroenterol Nutr 53:333-338. [PubMed: 21602717]

30. Hamatschek C, et al. 2020 Fat and Fat-Free Mass of Preterm and Term Infants from Birth to Six Months: A Review of Current Evidence. Nutrients 12.

31. Ellis KJ, et al. 2007 Body-composition assessment in infancy: air-displacement plethysmography compared with a reference 4-compartment model. Am J Clin Nutr 85:90-95. [PubMed: 17209182]

32. Demerath EW, et al. 2017 New body composition reference charts for preterm infants. Am J Clin Nutr 105:70-77. [PubMed: 27806978] 
33. Dung NQ, Fusch G, Armbrust S, Jochum F, Fusch C. 2007 Body composition of preterm infants measured during the first months of life: bioelectrical impedance provides insignificant additional information compared to anthropometry alone. Eur J Pediatr 166:215-222. [PubMed: 17047996]

34. Kiger JR, Taylor SN, Wagner CL, Finch C, Katikaneni L. 2016 Preterm infant body composition cannot be accurately determined by weight and length. J Neonatal Perinatal Med.

35. Ramel SE, Zhang L, Misra S, Anderson CG, Demerath EW. 2017 Do anthropometric measures accurately reflect body composition in preterm infants? Pediatr Obes 12 Suppl 1:72-77. [PubMed: 27635625]

36. Pfister KM, et al. 2018 Early body composition changes are associated with neurodevelopmental and metabolic outcomes at 4 years of age in very preterm infants. Pediatr Res 84:713-718. [PubMed: 30188501]

37. De Cunto A, et al. 2014 Can body mass index accurately predict adiposity in newborns? Arch Dis Child Fetal Neonatal Ed 99:F238-239. [PubMed: 24302686]

38. Johnson W, et al. 2017 Is infant body mass index associated with adulthood body composition trajectories? An exploratory analysis. Pediatr Obes 12:10-18. [PubMed: 26756208]

39. Kruithof CJ, Gishti O, Hofman A, Gaillard R, Jaddoe VW. 2016 Infant weight growth velocity patterns and general and abdominal adiposity in school-age children. The Generation R Study. Eur J Clin Nutr 70:1144-1150. [PubMed: 27071509] 




Figure 1.

Flow diagram 


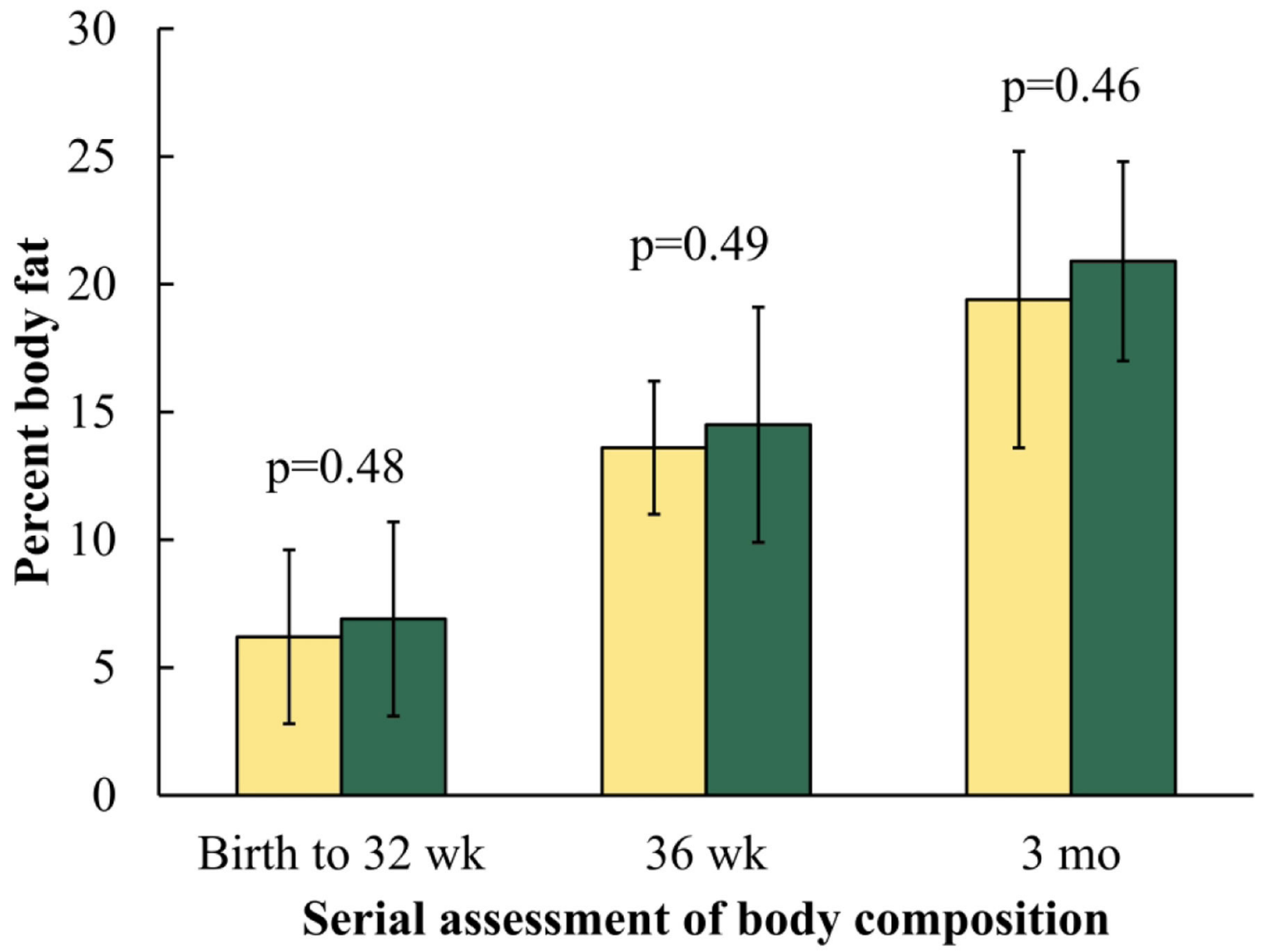

\section{$\square$ Control Group $\quad \square$ Intervention Group}

Figure 2.

Serial assessment of body fat accretion in very preterm infants 


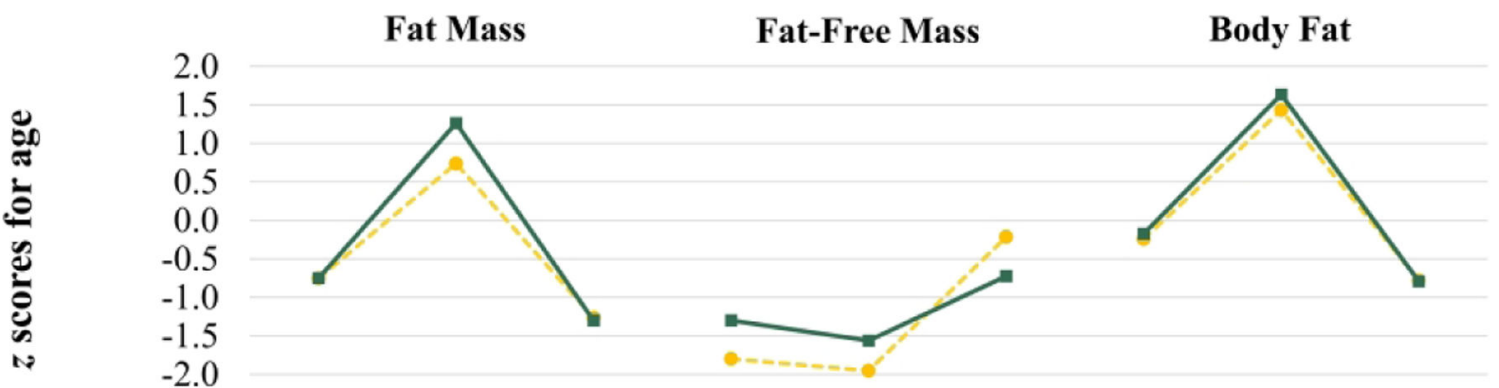

\begin{tabular}{|l|c|c|c|c|c|c|c|c|c|}
\cline { 2 - 10 } \multicolumn{1}{c|}{} & $32.5 \mathrm{wk}$ & $36 \mathrm{wk}$ & $3 \mathrm{mo}$ & $32 \mathrm{wk}$ & $36 \mathrm{wk}$ & $3 \mathrm{mo}$ & $32 \mathrm{wk}$ & $36 \mathrm{wk}$ & $3 \mathrm{mo}$ \\
\hline-- Control & -0.8 & 0.7 & -1.3 & -1.8 & -2.0 & -0.2 & -0.2 & 1.4 & -0.8 \\
\hline$\rightarrow-$ Intervention & -0.8 & 1.3 & -1.3 & -1.3 & -1.6 & -0.7 & -0.2 & 1.6 & -0.8 \\
\hline
\end{tabular}

Figure 3. Changes in body composition $\mathrm{z}$ scores between birth and 3 months corrected age*

* Differences between groups were not statistically significant 
Table 1.

Baseline characteristics*

\begin{tabular}{|c|c|c|}
\hline & Intervention group $(n=25)$ & Control group $(n=25)$ \\
\hline \multicolumn{3}{|l|}{ Demographic characteristics } \\
\hline Birth weight in grams, median (IQR) & $1423 \pm 295$ & $1353 \pm 273$ \\
\hline Gestational age in weeks, median (IQR) & $31(30-32)$ & $30(30-32)$ \\
\hline Weight-for-age $\mathrm{z}$ score at birth ${ }^{1}$, mean $\pm \mathrm{SD}$ & $-0.16 \pm 0.77$ & $-0.38 \pm 0.84$ \\
\hline Weight $<10^{\text {th }}$ percentile at birth ${ }^{1}, \mathrm{n}(\%)$ & $3(12)$ & $5(20)$ \\
\hline Male, n (\%) & $15(60)$ & $11(44)$ \\
\hline Black race, $\mathrm{n}(\%)$ & $11(44)$ & $12(48)$ \\
\hline Exposure to a full course ( 2 doses) of antenatal steroids, $\mathrm{n}(\%)$ & $22(88)$ & $22(88)$ \\
\hline Vaginal delivery, $\mathrm{n}(\%)$ & $10(40)$ & $6(24)$ \\
\hline Postnatal age when enteral feeding was initiated in days, median (IQR) & $3(2-4)$ & $3(2-4)$ \\
\hline $\begin{array}{l}\text { Postnatal age when > } 120 \mathrm{ml} / \mathrm{kg} \text { of enteral feeding was achieved in days, median } \\
\text { (IQR) }\end{array}$ & $8(7-9)$ & $8(7-9)$ \\
\hline Proportion of intake as mother's milk (>80\%) at postnatal day $7, \mathrm{n}(\%)$ & $17(68)$ & $16(70)$ \\
\hline Duration of parenteral nutrition in days, median (IQR) & $6(0-7)$ & $5(0-7)$ \\
\hline
\end{tabular}

Pediatr Res. Author manuscript; available in PMC 2021 January 07. 
Table 2.

Study outcomes

\begin{tabular}{|c|c|c|c|}
\hline Outcomes & Intervention group $(\mathbf{n}=\mathbf{2 5})$ & Control group $(n=25)$ & $\mathbf{p}$ \\
\hline \multicolumn{4}{|l|}{ Nutritional outcomes } \\
\hline Proportion of intake as mother's milk (>80\%) at 36 weeks, $\mathrm{n}(\%)$ & $8(32)$ & $10(40)$ & 0.56 \\
\hline Feeding volume at 36 weeks in $\mathrm{ml} / \mathrm{kg} / \mathrm{d}$, mean $\pm \mathrm{SD}$ & $161 \pm 21$ & $164 \pm 27$ & 0.63 \\
\hline Caloric intake at 36 weeks in cal $/ \mathrm{kg} / \mathrm{d}$, median (IQR) & $120(105-135)$ & $125(112-138)$ & 0.47 \\
\hline Protein intake at 36 weeks in $\mathrm{g} / \mathrm{kg} / \mathrm{d}$, median (IQR) & $4.0(1.8-4.5)$ & $4.0(3.2-4.4)$ & 0.83 \\
\hline Growth rate from birth to 36 weeks in $\mathrm{g} / \mathrm{kg} / \mathrm{d}$, mean $\pm \mathrm{SD}$ & $12 \pm 4$ & $12 \pm 3$ & 0.51 \\
\hline \multicolumn{4}{|l|}{ Anthropometric outcomes ${ }^{1}$} \\
\hline Weight-for-age $\mathrm{z}$ score at 36 weeks, mean $\pm \mathrm{SD}$ & $-1.1 \pm 0.9$ & $-1.3 \pm 1.0$ & 0.37 \\
\hline Length-for-age $\mathrm{z}$ score at 36 weeks, mean $\pm \mathrm{SD}$ & $-1.1 \pm 1.1$ & $-1.3 \pm 1.1$ & 0.99 \\
\hline Head circumference-for-age $\mathrm{z}$ score at 36 weeks, mean $\pm \mathrm{SD}$ & $-0.8 \pm 0.8$ & $-0.8 \pm 1.4$ & 0.97 \\
\hline Postnatal growth failure at 36 weeks (weight $<10$ th percentile), $\mathrm{n}(\%)$ & $11(40)$ & $14(56)$ & 0.40 \\
\hline $\begin{array}{l}\text { Difference between weight } \mathrm{z} \text { score at birth and weight } \mathrm{z} \text { score at } 36 \\
\text { weeks, mean } \pm \mathrm{SD}\end{array}$ & $-0.9 \pm 0.6$ & $-1.0 \pm 0.6$ & 0.90 \\
\hline Body composition outcomes at 36 weeks PMA & $\mathrm{n}=18$ & $\mathrm{n}=17$ & \\
\hline Postnatal age at assessment in days, median (IQR) & $35(29-48)$ & $32(28-37)$ & 0.12 \\
\hline Fat mass in $\mathrm{g}$, mean $\pm \mathrm{SD}$ & $315 \pm 133$ & $282 \pm 87$ & 0.39 \\
\hline Fat-free mass in $\mathrm{g}$, mean $\pm \mathrm{SD}$ & $1802 \pm 216$ & $1763 \pm 245$ & 0.62 \\
\hline$\%$ Body fat, mean \pm SD & $14 \pm 5$ & $14 \pm 3$ & 0.49 \\
\hline Body composition outcomes at 3 months CA & $\mathrm{n}=13$ & $\mathrm{n}=12$ & \\
\hline Postmenstrual age at assessment in weeks, median (IQR) & $54(53-55)$ & $53(52-56)$ & 0.60 \\
\hline Fat mass in $\mathrm{g}$, mean $\pm \mathrm{SD}$ & $1050 \pm 306$ & $1089 \pm 427$ & 0.79 \\
\hline Fat-free mass in $\mathrm{g}$, mean $\pm \mathrm{SD}$ & $3913 \pm 366$ & $4286 \pm 545$ & 0.06 \\
\hline$\%$ Body fat, mean \pm SD & $21 \pm 4$ & $19 \pm 6$ & 0.46 \\
\hline
\end{tabular}

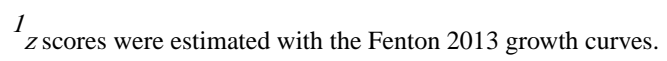

Pediatr Res. Author manuscript; available in PMC 2021 January 07. 